\title{
Extravascular lung water and pulmonary arterial wedge pressure for fluid management in patients with acute respiratory distress syndrome
}

\author{
Wei Hu*, Chang-Wen Lin, Bing-Wei Liu, Wei-Hang Hu and Ying Zhu
}

\begin{abstract}
Background: Extravascular lung water (EVLW) is a sensitive prognostic indicator of pulmonary edema. Thus, EVLW may be an advantageous method of fluid management. This study aims to evaluate the outcomes of using EVLW and pulmonary artery wedge pressure (PAWP) as strategies for fluid management in patients with acute respiratory distress syndrome (ARDS).

Methods: Twenty-nine patients were randomly divided into the EVLW and PAWP groups. The survival rate, ICU (Intensive Care Unit) length of stay, duration of mechanical ventilation, acute lung injury scores, and oxygenation index of the EVLW and PAWP groups were compared.

Results: No significant difference in the survival rates at 28 and 60 days (d) after treatment was found between the two groups $(p=0.542)$. The duration of mechanical ventilation and ICU length of stay were significantly lower $(p<0.05)$ in the EVLW group than in the PAWP group. The $7 \mathrm{~d}$ cumulative fluid balance was $-783 \pm 391 \mathrm{ml}$ in the EVLW group and $-256 \pm 514 \mathrm{ml}$ in the PAWP group $(p<0.05)$. Compared with the PAWP group, the EVLW group showed improved oxygenation index $(p=0.006)$.
\end{abstract}

Conclusions: EVLW for fluid management improved clinical results in patients with ARDS better than PAWP.

Keywords: Acute respiratory distress syndrome, Extravascular lung water, Fluid management, Pulmonary artery wedge pressure

\section{Background}

Acute respiratory distress syndrome (ARDS) is a lifethreatening form of lung injury that usually occurs with diseases, such as severe infection, multiple trauma, and burns. The condition occurs because of the diffuse pulmonary interstitial and alveolar edemas caused by the injury of pulmonary capillary and alveolar epithelial cells. When blood cells are low in oxygen, ARDS becomes a progressive disease that causes respiratory distress with extremely high mortality risk. Thus, ARDS is a serious threat that affects the quality of patients' lives. Increased capillary permeability is a pathophysiological hallmark of ARDS, and the severity of pulmonary edema is positively associated with the prognosis of ARDS [1]. Therefore, active fluid management is clinically important to

\footnotetext{
* Correspondence: weihucn@126.com

Department of Intensive Care Unit, the First People's Hospital of Hangzhou, Nanjing Medical University, Hangzhou 310006, China
}

ameliorate pulmonary edema. However, fluid management in ARDS patients is difficult because a sufficient volume must be supplied to resuscitate the patient while avoiding the occurrence or exacerbation of pulmonary edema [2]. Pulmonary arterial wedge pressure (PAWP) and central venous pressure (CVP) have long been used for clinical fluid management in ARDS patients. However, these methods are not accurate because the relationship among PAWP, CVP, and cardiac preload may be affected by several factors $[3,4]$. The pulse-indicating continuous heart displacement monitoring technology (pulse-induced contour cardiac output; PiCCO) was applied. Extravascular lung water (EVLW) has also been used as a sensitive prognostic indicator of pulmonary edema. EVLW has become an important hemodynamic parameter for bedside monitoring [5-7]. Thus, EVLW may be a more advantageous method of fluid management [7-9]. In this study, we evaluated and compared 
Table 1 The general characteristics of patients enrolled in the two groups

\begin{tabular}{|c|c|c|c|c|c|c|c|c|}
\hline \multirow[t]{2}{*}{ Groups } & \multirow{2}{*}{$\begin{array}{c}\mathbf{n} \\
\text { (cases) }\end{array}$} & \multicolumn{2}{|c|}{ Gender (cases) } & \multirow{2}{*}{$\begin{array}{c}\text { Age } \\
\text { (years) }\end{array}$} & \multirow{2}{*}{$\begin{array}{l}\text { APACHEa } \\
\text { score }\end{array}$} & \multirow{2}{*}{$\begin{array}{l}\text { SOFA } \\
\text { score }\end{array}$} & \multirow{2}{*}{$\begin{array}{l}\text { ALI score } \\
\text { at baseline }\end{array}$} & \multirow{2}{*}{$\begin{array}{l}\text { Oxygenation index at } \\
\text { baseline }(\mathrm{mmHg})\end{array}$} \\
\hline & & $M$ & $F$ & & & & & \\
\hline EVLW Group & 15 & 8 & 7 & $50 \pm 13$ & $22.20 \pm 3.14$ & $9.33 \pm 2.41$ & $2.78 \pm 0.45$ & $127.57 \pm 18.59$ \\
\hline PAPW Group & 14 & 9 & 5 & $49 \pm 12$ & $21.93 \pm 3.77$ & $9.36 \pm 2.34$ & $2.83 \pm 0.53$ & $133.73 \pm 22.92$ \\
\hline
\end{tabular}

Data are shown as mean \pm SD.

the outcomes of ARDS patients treated with fluid management by EVLW and PAWP.

\section{Subjects and methods \\ Patients}

This study was approved by the Ethics Committee. All 29 adult ARDS patients or their guardians signed an informed consent form upon recruitment and enrolment for this study. All patients were hospitalized at the ICU (Intensive Care Unit). Patients were diagnosed according to the American-European Consensus definition of ARDS provided in 1994: (a) acute onset; (b) bilateral infiltrates on chest radiograph consistent with pulmonary edema; (c) ratio of partial pressure of arterial oxygen $\left(\mathrm{PaO}_{2}\right)$ to fraction of inspired oxygen $\left(\mathrm{FiO}_{2}\right)$ less than 200; and (d) absence of left atrial hypertension. The study period lasted from January 2009 to November 2011. The study excluded patients with severe pulmonary hypertension, complete left bundle-branch block, pneumonectomy, interstitial lung disease, and bacterial endocarditis. Patients discharged against medical advice were also excluded.

The patients were randomly divided into the EVLW $(n=15)$ and PAWP $(n=14)$ groups. The causes of ARDS in the EVLW group included severe pneumonia $(n=6)$, abdominal infection $(n=3)$, multiple trauma $(n=2)$, $\mathrm{H}_{1} \mathrm{~N}_{1}(n=2)$, severe acute pancreatitis $(n=1)$, and irritant gas inhalation $(n=1)$. The causes of ARDS in the PAWP group included severe pneumonia $(n=5)$, abdominal infection $(n=3)$, multiple trauma $(n=1), \mathrm{H}_{1} \mathrm{~N}_{1}$ $(n=2)$, severe acute pancreatitis $(n=2)$, and urinary tract infection $(n=1)$. The general characteristics of the patients from the two groups are listed in Table 1. No significant differences were observed between the two groups $(\mathrm{p}>0.05)$.

\section{Methods}

All patients admitted to the ICU were treated by mechanical ventilation to manage the primary disease. Mechanical ventilation was performed according to the protective ventilation strategy recommended by the ARDS Network. In general, a pressure control ventilation or biphasic positive airway pressure mode was adopted, with the controlled peak airway pressure $<35 \mathrm{~cm} \mathrm{H}_{2} \mathrm{O}$, the plateau pressure $<30 \mathrm{~cm} \mathrm{H}_{2} \mathrm{O}$, and the force inspiratory oxygen and positive pressure respiration set according to titration.
The patients were evaluated using Acute Physiology and Chronic Health Evaluation II and Sequential Organ Failure Assessment scores. For the EVLW group, a standard central venous catheter (Arrow Electronics, New York, USA) was inserted into either the internal jugular or subclavian location, and an arterial catheter (Pulsion Medical Systems, Munich, Germany) was inserted into the descending aorta via the femoral artery using the Seldinger technique. During fluid management, EVLW was measured every $8 \mathrm{~h}$ and maintained within $3 \mathrm{ml} / \mathrm{kg}$ to $7 \mathrm{ml} / \mathrm{kg}$. When EVLW reached or exceeded $7 \mathrm{ml} / \mathrm{kg}$, the patient was treated with diuretics or continuous renal replacement therapy (CRRT). For the PAWP group, a Swan-Ganz floating catheter (Arrow Electronics, New York, USA) was inserted into the pulmonary artery using the Seldinger technique. PAWP was measured every $8 \mathrm{~h}$ and maintained within $8 \mathrm{~mm} \mathrm{Hg}$ to $12 \mathrm{~mm} \mathrm{Hg}$. When PAWP reached or exceeded $12 \mathrm{~mm} \mathrm{Hg}$, treatment with diuretics or CRRT was performed. All decisions on patient management, including fluid and ventilator management, were made by the primary intensive care physicians caring for the patient. This study was conducted in accordance with the declaration of Helsinki. The experiments were approved by the Ethics Committee of the first People's Hospital. Written informed consent was obtained from all participants.

\section{Outcome variables}

Vital signs, such as blood pressure, were recorded every hour. The $24 \mathrm{~h}$ intake and discharge fluid volume were also recorded daily. The acute lung injury score and oxygenation index were calculated every $24 \mathrm{~h}$. Survival rates at 28 and $60 \mathrm{~d}$ after treatment were taken as the primary endpoints. Finally, the ICU length of stay (ICU LOS)

\begin{tabular}{|c|c|c|c|c|}
\hline Groups & $\begin{array}{c}\text { Duration of } \\
\text { mechanical } \\
\text { ventilation (days) }\end{array}$ & $\begin{array}{l}\text { ICU length } \\
\text { of stay (days) }\end{array}$ & $\begin{array}{l}\text { Survival at } \\
28 \text { days (\%) }\end{array}$ & $\begin{array}{l}\text { Survival at } \\
60 \text { days (\%) }\end{array}$ \\
\hline $\begin{array}{l}\text { EVLW } \\
\text { group }\end{array}$ & $10.13 \pm 3.02^{*}$ & $12.53 \pm 3.50^{*}$ & 73.33 & 73.33 \\
\hline $\begin{array}{l}\text { PAWP } \\
\text { group }\end{array}$ & $12.64 \pm 2.89$ & $15.50 \pm 2.50$ & 78.57 & 78.57 \\
\hline
\end{tabular}

Data are shown as mean $\pm S D,{ }^{*} p<0.05$ versus PAWP values. 
Table 3 Comparison of acute lung injury score in the two groups

\begin{tabular}{|c|c|c|c|c|c|c|}
\hline Groups & Prior treatment & The first day post-treatment & The third day post-treatment & The fifth day post-treatment & $F$ & $\mathbf{p}$ \\
\hline EVLW group & $2.783 \pm 0.452$ & $2.667 \pm 0.654^{*}$ & $2.311 \pm 0.526^{*}$ & $1.867 \pm 0.516^{*}$ & 8.678 & 0.000 \\
\hline PAWP group & $2.826 \pm 0.526$ & $2.738 \pm 0.587^{*}$ & $2.381 \pm 0.582^{*}$ & $2.092 \pm 0.546^{*}$ & 5.092 & 0.003 \\
\hline$t$ & 0.237 & 0.307 & 0.340 & 1.141 & 1.302 & 0.273 \\
\hline$p$ & 0.815 & 0.761 & 0.736 & 0.264 & & \\
\hline
\end{tabular}

Data are shown as mean $\pm S D,{ }^{*} p<0.05$ versus prior treatment.

was determined as a secondary endpoint to evaluate the curative effect.

\section{Statistical analysis}

Statistical analysis was performed using the software program SPSS (version 18.0; Chicago, IL, USA). Enumerated data were compared using Fisher's exact test. Continuous data were presented as mean \pm standard deviation and compared using two-sample $t$-tests. Variance analysis was used for the comparisons of data before and after treatment. All statistical tests were two-sided; $\mathrm{p}<0.05$ was considered to indicate statistical significance.

\section{Results}

\section{Duration of mechanical ventilation, ICU LOS, fluid} balance, and patient survival

The duration of mechanical ventilation and the ICU LOS of patients were significantly lower in the EVLW group than in the PAWP group $(t=2.283$ and $t=2.612$, respectively; $\mathrm{p}<0.05$ for both). The $7 \mathrm{~d}$ cumulative fluid balance was $-783 \pm 391 \mathrm{ml}$ in the EVLW group and $-256 \pm 514 \mathrm{ml}$ in the PAWP group $(\mathrm{p}<0.05)$. Nevertheless, no significant differences were observed in the number of survivors at 28 and $60 \mathrm{~d}$ after treatment between the two groups $(p=0.542$ for both; Table 2).

\section{Acute lung injury scores}

After treatment with EVLW or PAWP, the acute lung injury scores of the patients gradually decreased. This result differed significantly at 1,3 , and $5 \mathrm{~d}$ after treatment $(\mathrm{p}<0.05)$. However, the scores between the two treatment groups were not significantly different $(F=1.302$, $\mathrm{p}=0.273$; Table 3).

\section{Oxygenation index}

The oxygenation index dramatically enhanced in the EVLW and PAWP groups as the treatment was continued ( $\mathrm{p}<0.05$ for both groups). Significant differences were observed between the two groups $(F=6.437$, $\mathrm{p}=0.006$; Table 4).

\section{Discussion}

ARDS usually occurs with noncardiogenic diseases, such as severe infection, shock, trauma, and burns. ARDS is caused by pulmonary edema in the interstitial and alveolar cells, which can be attributed to the damage of pulmonary capillary and alveolar epithelial cells. Pathophysiologically, increased capillary permeability impairs fluid removal from the alveolar space. The accumulation of protein-rich fluids inside the alveoli severely reduces lung volume and lung compliance, as well as disturbs the ventilation-perfusion ratio. ARDS becomes apparent with progressive hypoxemia, clinical respiratory distress, and the heterogeneity of exudative process in chest radiography [10].

To date, fluid management in patients with ARDS remains an intractable problem. Venous fluid infusion is important for patients with severely damaged pulmonary ventilation to maintain a suitable inner capacity and, consequently, to stabilize blood dynamics and infusion into major organs. However, excess fluid would worsen pulmonary edema and thus damage gas exchange. The strategies used in ICUs for fluid management are classified into two categories: 1) the opening fluid management strategy or wet approach and 2) the restricted or conserved fluid management strategy or dry approach [11]. The ARDS network showed that mortality is not significantly different between the restricted and unrestricted fluid management strategies. However, patients

Table 4 Comparison of oxygenation index in the two groups

\begin{tabular}{|c|c|c|c|c|c|c|c|}
\hline Groups & Prior treatment & $\begin{array}{l}\text { The first day } \\
\text { post- treatment }\end{array}$ & $\begin{array}{l}\text { The third day } \\
\text { post- treatment }\end{array}$ & $\begin{array}{c}\text { The fifth day } \\
\text { post- treatment }\end{array}$ & $\begin{array}{c}\text { The fifth day } \\
\text { post- treatment }\end{array}$ & $F$ & $\mathrm{p}$ \\
\hline EVLW group & $127.568 \pm 18.592$ & $147.066 \pm 21.339^{*}$ & $173.266 \pm 23.251^{*^{\Delta}}$ & $191.333 \pm 21.053^{*^{\Delta}}$ & $210.066 \pm 26.547^{* \Delta}$ & 33.118 & 0.000 \\
\hline PAWP group & $133.733 \pm 22.917$ & $156.000 \pm 26.94^{*}$ & $157.857 \pm 21.565^{*}$ & $174.571 \pm 16.232^{*}$ & $185.571 \pm 17.261^{*}$ & 12.024 & 0.000 \\
\hline$t$ & 0.798 & 0.996 & -1.847 & -2.388 & -2.922 & 6.347 & 0.006 \\
\hline$p$ & 0.431 & 0.329 & 0.076 & 0.024 & 0.007 & & \\
\hline
\end{tabular}

Data are shown as mean $\pm S D,{ }^{*} p<0.05$ versus prior treatment. ${ }^{\triangle} p<0.05$ versus PAWP group. 
with restricted fluid management (i.e., treatment with diuretics and limited fluid infusion) experience a negative fluid balance on the first week $(-136 \pm 491 \mathrm{ml}$ vs. $6992 \pm$ $502 \mathrm{ml}$ for unrestricted). Compared with unrestricted fluid management, restricted fluid management yields improved oxygenation index, significantly reduced lung injury score, and significantly shorter ICU LOS [12]. Given the premise of maintaining a stable cycle and organ perfusion, the use of restricted fluid management is more favorable for ARDS patients.

The methods for extenuating pulmonary edema may notably reduce the cardiac output and organ filling defect; however, the incidence of dysfunction in other organs is increased $[2,13]$. In the present study, the incidence of shock and hypotension did not increase, even when restricted fluid management was used in combination with treatment using diuretics or CRRT. This result may be attributed to our small sample size. Further prospective clinical studies should be performed.

EVLW is a unique method for quantitatively monitoring the injury and permeability of pulmonary capillaries. This parameter is considered an independent risk factor to predict the severity and prognosis of critically ill patients $[8,9,14-16]$. During the progression of ARDS, the pneumonic oxygenation index and static compliance sharply decrease as EVLW increases [8,17]. Furthermore, CVP and PAWP cannot accurately reflect the changes in pulmonary edema during an illness because the data are influenced by the altered permeability of the capillaries and the mechanical ventilation being used $[3,4,18,19]$. Due to time and objective case constraints, the sample size in this study is small, and there is no significant difference at primary endpoint between two groups. Conditions permitting, the sample size should be enlarged for further investigation.

\section{Conclusions}

The prognosis of ARDS can be influenced by several factors, such as age, primary diseases, and complications due to multiple organ failure or severe sepsis. These factors are closely associated with the high fatality rate of ARDS. Despite the absence of evidence that the negative fluid balance can be used as an independent prognostic factor, the results of this study showed that EVLW for restricted fluid management improves the oxygenation index better than PAWP. Thus, the duration of mechanical ventilation and ICU LOS can be reduced. Although no significant differences in the overall mortality were observed between the two treatments, EVLW has more clinical value than PAWP in terms of fluid management in patients with ARDS.

\section{Competing interests}

The authors declare that they have no competing interests.

\section{Acknowledgements}

The authors want to thank Prof. Wei Cui from The Second Affiliated Hospital of Zhejiang University School of Medicine for his technical guidance and support on PiCCO.

Received: 28 September 2013 Accepted: 7 January 2014 Published: 16 January 2014

\section{References}

1. Ware LB, Matthay MA: The acute respiratory distress syndrome. N Engl J Med 2002, 342:1334-1349.

2. Murphy CV, Schramm GE, Doherty JA, Reichley RM, Gajic O, Afessa B, Micek ST, Kollef MH: The importance of fluid management in acute lung injury secondary to septic shock. Chest 2009, 136:102-109.

3. Colmenero M, Pérez Villares JM, Fernández Sacristán MA, Garcia Delgado M, FernándezMondéjar E: Effect of pulmonary artery pressure on extravascular lung water in an experimental model of acute lung injury. Acta Anaesthesiol Scand 2005, 49:1449-1455.

4. Martin GS, Eaton S, Mealer M, Moss M: Extravascular lung water in ill patients with severe sepsis: a prospective cohort study. Crit Care Med 2005, 9:74-82.

5. Sakka SG, Klein M, Reinhart K, Meier-Hellmann A: Prognostic value of extravascular lung water in critically ill patients. Chest 2002, 122:2080-2086

6. Patroniti N, Bellani G, Maggioni E, Manfio A, Marcora B, Pesenti A: Measurement of pulmonary edema in patients with acute respiratory distress syndrome. Crit Care Med 2005, 33:2547-2554.

7. Phillips CR, Chesnutt MS, Smith SM: Extravascular lung water in sepsisassociated acute respiratory distress syndrome: indexing with predicted body weight improves correlation with severity of illness and survival. Crit Care Med 2008, 36:69-73.

8. Berkowitz DM, Danai PA, Eaton S, Moss M, Martin GS: Accurate characterization of extravascular lung water in acute respiratory distress syndrome. Crit Care Med 2008, 36:1803-1809.

9. Craig TR, Duffy MJ, Shyamsundar M, McDowell C, McLaughlin B, Elborn JS, McAuley DF: Extravascular lung water indexed to predicted body weight is a novel predictor of intensive care unit mortality in patients with acute lung injury. Crit Care Med 2010, 38:114-120.

10. Bernard GR, Artigas A, Brigham KL, Carlet J, Falke K, Hudson L, Lamy M, Legall JR, Morris A, Spragg R: The American-European consensus conference on ARDS: definitions, mechanisms, relevant outcomes, and clinical trial coordination. Am J Respir Crit Care Med 1994, 149:818-824

11. Fernández-Mondéjar E, Guerrero-López F, Colmenero M: How important is the measurement of extravascular lung water? Curr Opin Crit Care 2007, 13.79-83.

12. Wiedemann HP, Wheeler AP, Bernard GR, Thompson BT, Hayden D, de Boisblanc B, Connors AF Jr, Hite RD, Harabin AL: Comparison of two fluidmanagement strategies in acute lung injury. N Engl I Med 2006, 354:2564-2575

13. Rizvi K, Deboisblanc BP, Truwit JD, Dhillon G, Arroliga A, Fuchs BD, Guntupalli KK, Hite D, Hayden D: Effect of airway pressure display on interobserver agreement in the assessment of vascular pressures in patients with acute lung injury and acute respiratory distress syndrome. Crit Care Med 2005, 33:98-103.

14. Kuzkov W, Kirov MY, Sovershaev MA, Kuklin VN, Suborov EV, Waerhaug K, Bjertnaes LJ: Extravascular lung water determined with single transpulmonarythermodilution correlates with the severity of sepsis-induced acute lung injury. Crit Care Med 2006, 34:1647-1653.

15. Berkowitz DM, Martin G: Extravascular lung water measurement in acute respiratory distress syndrome. Crit Care Med 2009, 37:378.

16. LeTourneau JL, Pinney J, Phillips CR: Extravascular lung water predicts progression to acute lung injury in patients with increased risk. Crit Care Med 2012, 40:847-854

17. Easley RB, Mulreany DG, Lancaster CT, Custer JW, FernandezBustamante A, Colantuoni E, Simon BA: Redistribution of pulmonary blood flow impacts thermodilution-based extravascular lung water measurements in a model of acute lung injury. Anesthesiology 2009, 111:1065-1074. 
18. Boussat S, Jacques T, Levy B, Laurent E, Gache A, Capellier G, Neidhardt A: Intravascular volume monitoring and extravascular lung water ill septic patients with pulmonary edema. Intensive Care Med 2002, 28:712-718.

19. Hudson $E$, Beale R: Lung water and blood volume measurements in critically ill. Curr Opin Crit Care 2000, 6:222-226.

doi:10.1186/2049-6958-9-3

Cite this article as: Hu et al.: Extravascular lung water and pulmonary arterial wedge pressure for fluid management in patients with acute respiratory distress syndrome. Multidisciplinary Respiratory Medicine 2014 9:3.

\section{Submit your next manuscript to BioMed Central and take full advantage of:}

- Convenient online submission

- Thorough peer review

- No space constraints or color figure charges

- Immediate publication on acceptance

- Inclusion in PubMed, CAS, Scopus and Google Scholar

- Research which is freely available for redistribution 